\title{
Communication and Presentation Skills - A Little Help Goes a Long Way
}

Verna Rhodes

Access \& Widening Participation Unit

One of the responsibilities of the Access \& Widening Participation Unit (AWPU) team at the University of Greenwich is to help students to make a successful progression into higher education. Whilst working with local schools, sixth form centres and colleges, we deliver a wide range of projects in order to support the development and delivery of general and subject specific activities.

Amidst the rising demand for young people to demonstrate a higher standard of communication skills, one of the most popular requests for sixth form support includes help with presentations, not least because part of the Extended Project Qualification (EPQ) includes an assessed presentation. $E P Q$ is a free-standing qualification and a compulsory part of the diploma. EPQ is awarded for an extended piece of work at Level 3 of the National Qualifications Framework.

At the Negus Sixth Form Centre (Plumstead Manor School), a target group of 23 students, from a widening participation cohort, joined a presentation project in order to receive academic support for their extended project. The aim was to deliver a one-hour workshop to all of the students in order to prepare them for the assessed presentation. Materials were used from the SpeakersBank organisation, such as the top 10 tips for speaking in public and how to overcome nerves (SpeakersBank). All students were required to deliver a 10 to 15 minute presentation on their chosen topic (for which they had already written an essay).

Last January Andrew Sinclair, Study Skills Lecturer, held a workshop on presentation skills and, as expected, we were met with 23 'presentation phobic' students. However, all of the students were eager to find out how to give a presentation but not necessarily keen on the idea of practising for it, especially in front of their peers. Nevertheless, the task was set and each student was required to speak for two minutes on a topic of their choice. Unsurprisingly, each student's presentation varied considerably with almost all of them suffering from severe nerves and a lack of confidence.

We decided therefore to offer one-to-one tutorial support the following week in order to provide the students with more presentation techniques and thus increase their confidence. A total of twelve one-to-one tutorials were undertaken. Each student came with their prepared, or partly prepared, PowerPoint presentation and eagerly listened to advice and guidance on structure, layout, focus, content and timing. The deadline was looming for the assessed presentations at the end of the month and I readily agreed to assist with the assessment programme. 
All of the students delivered a satisfactory presentation, many of them delivered a very good presentation and some of them were absolutely excellent. One student deserved commendation for a presentation on the broad topic of the U.S. Health System versus the NHS; she had managed to deliver a carefully structured presentation with clear and easy to follow focus points within the time constraints.

However, another student gave an unexpected and simply staggering performance; having stood up in the initial workshop unable to deliver a full sentence because of rising panic and a severe lack of confidence, he gave a 15 minute presentation with all of the required methodology alongside a good dose of passion. Without doubt, the progress of this student had been outstanding - in just a few weeks he had managed to deliver a superb presentation of which he could be very proud.

Practising was not the only factor involved. As Anderson et al. remark, "Becoming a more effective communicator is not simply a matter of practicing the spoken language; practice certainly helps, but the real improvements come from planning how to approach a speaking task and evaluating how well you spoke." (Anderson et al. 2004).

With the ease of access to communication via the Internet (tools such as email, MSN, Facebook and Twitter) it is not difficult to demonstrate the decreasing forum for face-to-face communication. Practising is not the only remedy to overcome the problem; planning should certainly provide a starting point to encourage young and adult learners, with evaluation as part of the process of reflection to plan better next time.

\section{References}

Anderson, K., Maclean, J., and Lynch, T. (2004). Study speaking. Second edition, Cambridge: Cambridge University Press.

SpeakersBank. (2010). [Online]. Available at: www.SpeakersBank.co.uk. 